\title{
SEM/STEM observation of magnetic minerals in presumably unremagnetized Paleozoic carbonates from Indiana and Alabama
}

\author{
Dongwoo Suk, Rob Van der Voo and Donald R. Peacor \\ Department of Geological Sciences, University of Michigan, Ann Arbor, MI, 48109-1063, USA
}

(Received March 5, 1992; revised version accepted August 24, 1992)

\begin{abstract}
Suk, D. Van der Voo, R. and Peacor, D.R., 1992. SEM/STEM observation of magnetic minerals in presumably unremagnetized Paleozoic carbonates from Indiana and Alabama. Tectonophysics, 215: 255-272.

The Silurian Wabash Formation in Indiana and the Mississippian Pride Mountain Formation in Alabama appear not to have been affected by a late Paleozoic remagnetization event. In an attempt to characterize the magnetic mineralogy in these (presumably) unremagnetized carbonates and in order to compare their magnetic mineralogy to that of remagnetized carbonates, scanning and scanning transmission microscope (SEM/STEM) observations and rock magnetic investigations were carried out.

It is possible to recognize differences in magnetic mineralogy in the unremagnetized carbonate from that in remagnetized carbonates: (1) iron oxides associated with iron sulfides are hematite (in this study) as a result of replacement of pyrite (instead of magnetite as was found elsewhere); (2) occurrences of large euhedral pure-iron oxides of secondary origin are common in the unremagnetized carbonates; and (3) a rare occurrence of fine-grained single-crystal magnetite capable of carrying a remanence in the unremagnetized carbonates is noticeable as compared to the abundance of such grains in the remagnetized carbonates. Although the abundance of the fine-grained magnetite grains in remagnetized carbonates is inferred to be a diagnostic factor to distinguish the remagnetized from the unremagnetized carbonates, this clarifies only the carriers in the remagnctized rocks and leaves the question of the carricrs in unremagnetized limestones unresolved to a large extent.

The lack of remagnetization is commonly attributed to a restricted amount of fluid influx into the rocks. For the Wabash and the Pride Mountain Formations this may also be true; early cementation has significantly reduced the porosity and permeability in the Wabash Formation in Indiana, whereas the presence of the impermeable Chattanooga Shale may have 'protected' the Mississippian Pride Mountain Formation in Alabama.
\end{abstract}

\section{Introduction}

A late Paleozoic remagnetization has been widely recognized in many of the early to middle Paleozoic carbonates in eastern North America as having been acquired during the Kiaman reversed Polarity Superchron of the late Paleozuic (Kent, 1979; Scotese et al., 1982. McCabe et al., 1983, 1984; Bachtadse et al., 1987; Jackson et al., 1988). Although the remagnetization was an initial disappointment to paleomagnetists who hoped

Correspondence to: D. Suk, Department of Geology and Geophysics, University of Utah, 717 Browning Bldg., Salt Lake City, UT 84112, USA. to find reliable primary remanence for apparent polar wander path (APWP) construction, the causes and possible carriers of the remagnetization rapidly became interesting topics in and of themselves. The ancient remagnetization has been found not only in areas affected by major tectonic activity but also in the stable mid-continent where the effects of tectonic activity are less prominent (Lu et al., 1990). There have been two different explanations for the remagnetization, a CRM (chemical remanent magnetization) and a VRM (viscous remanent magnetization). A CRM mechanism, in which the magnetization was acquired during the formation of new magnetic minerals in limestones (McCabe et al., 1983, 1984; Bachtadse 
et al., 1987; Suk et al., 1990a,b) has generally been favored over the VRM model (Kent, 1985). Moreover, it is now generally accepted that fluid is a necessary ingredient in authigenesis of magnetic minerals in the remagnetized carbonates.

Despite the pervasive and widespread remagnetization in early to middle Paleozoic carbonates, several carbonates have nevertheless been found not to have been affected by the late Paleozoic remagnetization. The Silurian Wabash Formation in Indiana (McCabe et al., 1985), the Lower Ordovician Oneota dolomite from the upper Mississippi River Valley in Iowa, Wisconsin and Minnesota (Jackson and Van der Voo, 1985), and the Mississippian Pride Mountain Formation in Alabama (McCabe et al., 1989) have been inferred to have paleomagnetic directions of depositional ages; at the very least, no evidence for later Paleozoic remagnetization has been revealed by the paleomagnetic investigations. Whereas the remagnelized Paleozoic carbonates in eastern North America contain authigenic magnctite grains as a possible remanence carrier (Suk et al., 1990a,b), the unremagnetized carbonates were not expected to contain such secondary iron oxides; if that were the case, one could then conclude that the latter rocks did not experience the authigenesis that caused the introduction of new magnetic minerals long after the formation of the rocks. Instead, the unremagnetized carbonates have hitherto been inferred to contain magnetic minerals of detrital or near-primary (early diagenetic) origin. This speculation was supported by the presence of titaniferous iron oxide grains found in magnetic extracts from Mississippian carbonates in Alabama (McCabe et al., 1989). Those titaniferous magnetite grains, which displayed high-temperature oxidation exsolution textures, constitute the only direct evidence for a possible magnetic carrier of the primary magnetization in the unremagnetized carbonates. McCabe and colleagues (1989) attributed the lack of remagnetization to at most a limited amount of magnetite-forming fluid restricted by an impermeable shale horizon between older carbonates and the Mississippian carbonates in Alabama.

Since our successful characterization of iron oxides in the remagnetized carbonates from sev- eral localities in the northeastern U.S.A. in our previous scanning and scanning transmission electron microscope (SEM/STEM) investigations (Suk et al., 1990a,b, 1992), we have extended our studies to the unremagnetized carbonates in the hope that they can provide a representative picture of the magnetic mineralogy in pristine carbonates. If so, such studies could in turn lead to a better understanding of the remagnetization processes by allowing us to discriminate between the remagnetized and unremagnetized carbonates on the basis of their oxide textures, morphologies, modes of occurrence, chemistry, or mineralogy.

\section{Sample localities and methods}

The Silurian Wabash carbonates in Indiana and the Mississippian Pride Mountain carbonate in Alabama were sampled for this study. Samples of the Silurian Wabash Formation were collected from two localities in north-central Indiana: one is a small outcrop in a railroad cut near the town of Wabash, and the other is in the Pipe Creek Jr. Quarry near Gas City. These two localities are the same as those for the paleomagnetic study of McCabe et al. (1985). The Wabash Formation is divided into three principal lithofacies in the Pipe Creek Jr. Quarry; grainstone, grainstone-mudstone, and mudstone lithofacies (Devaney et al., 1986). The Wabash Formation in the quarry is dominantly limestone with minor dolomitic mudstone, while it is completely dolomite in the railroad outcrop. About $20 \mathrm{~kg}$ of carbonate samples of grainstone-mudstone lithofacies and dolomite from the quarry and dolomite from the outcrop in the railroad cut were collected for SEM/STEM observations of thin sections and magnetic extracts, and for rock magnetic experiments (Fig. 1). The Mississippian carbonate from a quarry in Margerum, Alabama, was provided by C. McCabe (see McCabe et al., 1989).

Representative samples were prepared for SEM/STEM observations as polished thin sections using "sticky wax" as an adhesive so that selected areas could be detached for STEM sample preparation. Areas containing iron oxides, as identified by SEM, were prepared for STEM 
observations using an ion mill to produce thin edges [see Suk et al. (1990a) for detailed description]. In addition, magnetic extracts were recovered from insoluble residues produced by dissolving limestones with buffered acetic acid (McCabe et al., 1983). For the Mississippian limestone from Alabama, dichloromethane was used to remove heavy bitumen in the rock prior to the acetic acid treatment. The magnetic separates were then spread on slides or on $\mathrm{Cu}$ grids in preparation for SEM and STEM observations, respectively. Several grains of selected separates were mounted on glass fibers to obtain Gandolfi powder X-ray diffraction patterns for mineral identification.

The SEM used is a Hitachi S-570, equipped with a Kevex Quantum energy-dispersive spectroscopic (EDS) system for X-ray analysis. The STEM used is a Philips CM-12 which is also equipped with a Kevex Quantum EDS system. The STEM is capable of much higher magnification than the SEM, but more importantly it provides selected area electron diffraction (SAED) patterns for definition of crystal structure.

Magnetic characterizations for representative samples of these carbonates were carried out at the paleomagnetic laboratory of the University of
Michigan to identify magnetic minerals, size and domain state, and magnetic interaction between magnetic minerals. Saturation isothermal remanent magnetization (SIRM) acquisition curve was obtained by imparting an isothermal remanent magnetization (IRM) in a stepwise manner at 12 steps to a maximum available field of $1.4 \mathrm{~T}$. Modified Lowrie-Fuller tests (I owrie and Fuller, 1971; Johnson et al., 1975) were carried out through acquisition and alternating field (AF) demagnetization of IRM and anhysteretic remanent magnetization (ARM). The ARM was induced using a $100 \mathrm{mT}$ AF field with a $0.1 \mathrm{mT}$ DC bias field, and the IRM was acquired using a 0.1-T DC field. These laboratory-induced magnetizations were demagnetized in a Schonstedt AF demagnetizer up to a peak induction field of 0.1 $T$ for the modified Lowrie-Fuller test. AF demagnetization curves of SIRM were plotted with the SIRM acquisition curve for the Cisowski test (Cisowski, 1981). A partial ARM (pARM) was also imparted on the specimens using a pARM switching device that turns on and off a DC bias field at a preset point for a given width of alternating field in a conventional AF demagnetizer (Jackson et al., 1988).

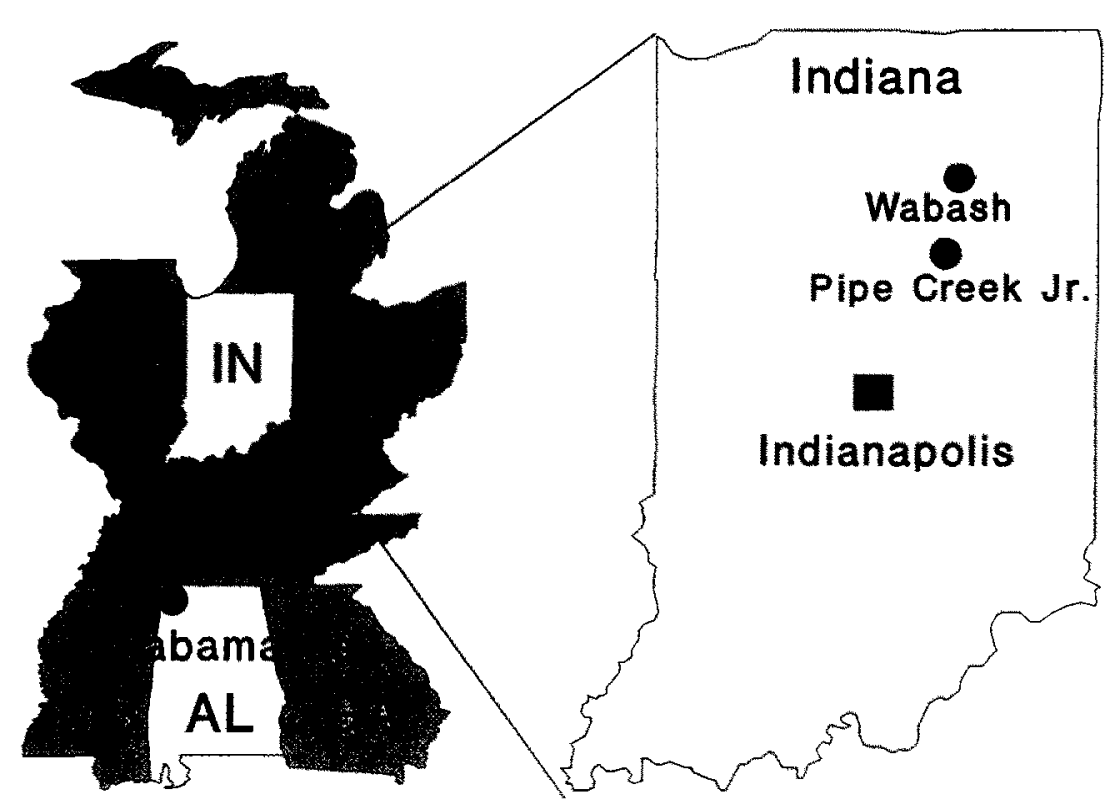

Fig. 1. Map of the study areas showing the locations of sampling localities (solid circles). 


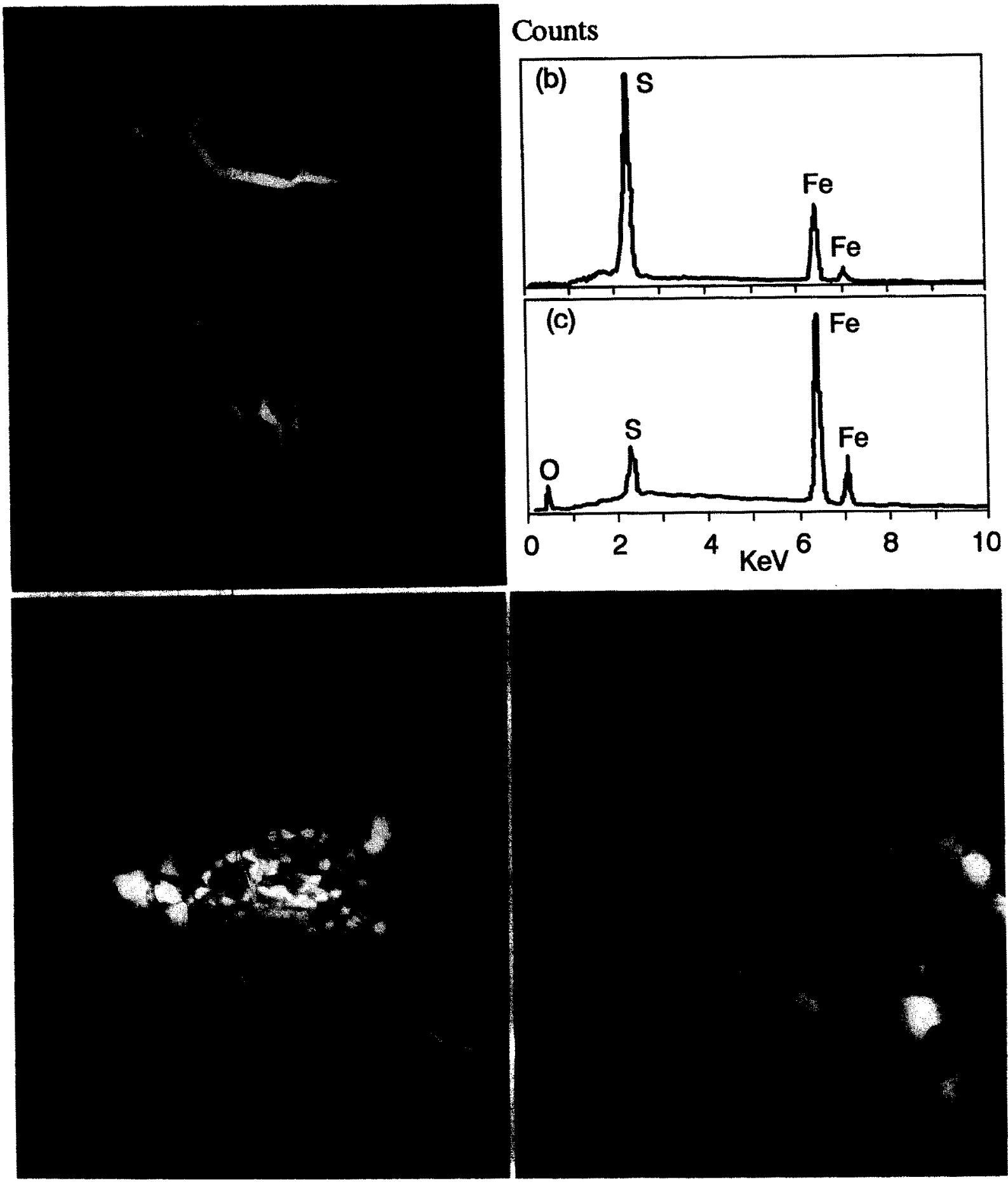

Fig. 2. Scanning electron microscopy photographs of iron-bearing minerals in thin sections of the Wabash and the Pride Mountain Formations. Symbols are: $I O=$ iron oxide; $P=$ pyrite; $D=$ dolomite; and $K=\mathrm{K}$-feldspar. (a) Oxide-sulfide assemblages along microcracks / pore spaces in dolomite. Sample is from the Pipe Creek Jr. Quarry; secondary electron image (SEI). (b) Energy-dispersive spectroscopic (EDS) spectrum from iron sulfide $(P)$ area shown in Fig. 2a, showing typical composition of pyrite. (c) EDS spectrum from iron oxide $(I O)$ area shown in Fig. 2a, showing a mixture of iron oxide and some sulfide. (d) Iron oxide-sulfide assemblage in a form of pseudoframboid. Pride Mountain Formation, Alabama. (e) Aggregates of iron oxides filling a cavity in dolomite grain. Iron sulfide $(P)$ grains are also seen. Pride Mountain Formation, Alabama. 


\section{Results}

\section{SEM / STEM observations}

Several types of iron oxides were identified either in thin sections or in magnetic extracts of rocks of both formations. Hematite as a replacement of pyrite was the most abundant magnetic phase in thin sections of the Wabash Formation as well as of the Pride Mountain carbonate. Less frequently, magnetite/hematite spherules, magnetite grains of $2-3 \mu \mathrm{m}$ in size as single-crystal and /or polycrystalline forms, well preserved euhedral iron oxides in an octahedral form inferred to be magnetite, and homogeneous Fe-Ti oxide grains were observed in magnetic extracts. Although it is rare, one cluster of single-crystal magnetite grains of about $0.05 \mu \mathrm{m}$ in size was observed in magnetic extracts as one of the more likely/plausible remanence carriers for the carbonates.

Typical iron oxide-sulfide phases for the Wabash Formation as they are seen in thin sections are shown in Figure 2a, where areas of bright contrast (labelled P) consist of pyrite surrounded by iron oxide (in medium contrast, labelled IO). The bright contrast areas are identified as pyrite (Fig. 2b) through energy-dispersive spectroscopic (EDS) analyses, whereas EDS spectra from the medium-contrast areas (Fig. 2c) always indicate $\mathrm{S}$ in addition to $\mathrm{Fe}$, as consistent with mixtures of iron oxide and iron sulfide. The dolomitic mudstone contained more iron oxidesulfide grains than the limestone counterpart. SEM observations of thin sections of the Pride Mountain carbonate revealed occurrences of iron oxide minerals similar to those in the Wabash Formation. However, iron oxide-sulfide assemblages as the predominant phase in the form of pseudoframboids (Fig. 2d) are more common in the Pride Mountain carbonate than irregularly shaped grains. Pyrite crystals are readily visible in this image as grains with bright contrast (labelled $P$ in Fig. 2d) and iron oxides are indicated by medium-contrast areas (labelled IO in Fig. 2d). Also, aggregates of sub-micron sized iron oxides filling a cavity in dolomite (Fig. 2e) were observed. Several grains with rather bright contrast (labeled $\mathrm{P}$ in Fig, 2e) have EDS spectra close to that of pyrite (e.g., Fig. 2b).

STEM observations were carried out for selected specimens in an attempt to identify the iron oxide-sulfide assemblages located by SEM. A grain of about $2 \mu \mathrm{m}$ in size showing iron oxide-sulfide relations in the Wabash carbonate was prepared for STEM observations. The iron oxide (Fig. 3a) is determined to be polycrystalline hematite based on the SAED ring patterns (Fig. 3b) taken from the thin edges. A dark field image (Fig. 3a), obtained from such an SAED pattern, has bright spots corresponding to individual hematite crystallites concentrated in the rim. Individual crystallites are in the size range of 5-50 nm. STEM observations of iron oxides located by SEM in thin sections of the Pride Mountain carbonate revealed that a sub-micron size crystal (Fig. 3c), from a pseudoframboidal iron oxide, also consists of polycrystalline hematite in its thin edges. The polycrystalline nature of the grain is verified by a SAED ring pattern of hematite (Fig. 3d). In a dark field image of the grain (Fig. 3c) taken in STEM mode, bright spots are the areas that contributed to the SAED ring pattern of hematite. Each bright spot in Figure $3 \mathrm{c}$ represents an individual single hematite crystal on the order of several hundredths to a few tenths of micrometer in size. The textural relations imply that such hematite is a replacement of pyrite.

Although pure spherical iron oxides were not observed in thin sections, we did find spherical iron oxide grains with only $\mathrm{Fe}$ and $\mathrm{O}$ (Fig. 4a) commonly in magnetic extracts. One such spheroid was identified as magnetite by X-ray diffraction using a Gandolfi camera. These spherical magnetite grains have morphologies similar to those found in the remagnetized carbonates. Spherical iron oxide (Fig. 4b) with Fe, O, and S were also observed in magnetic extracts. These iron oxide spherules containing $S$ have similarities in morphology and composition to the pseudoframboidal iron oxide-sulfide assemblages observed in thin sections (Fig. 2d) of the Pride Mountain carbonates. In the latter, hematite resulted from replacement of pyrite (Fig. 3c); thus the iron oxide spherules with $S$ in Figure $4 b$ are inferred to be hematite spherules. 


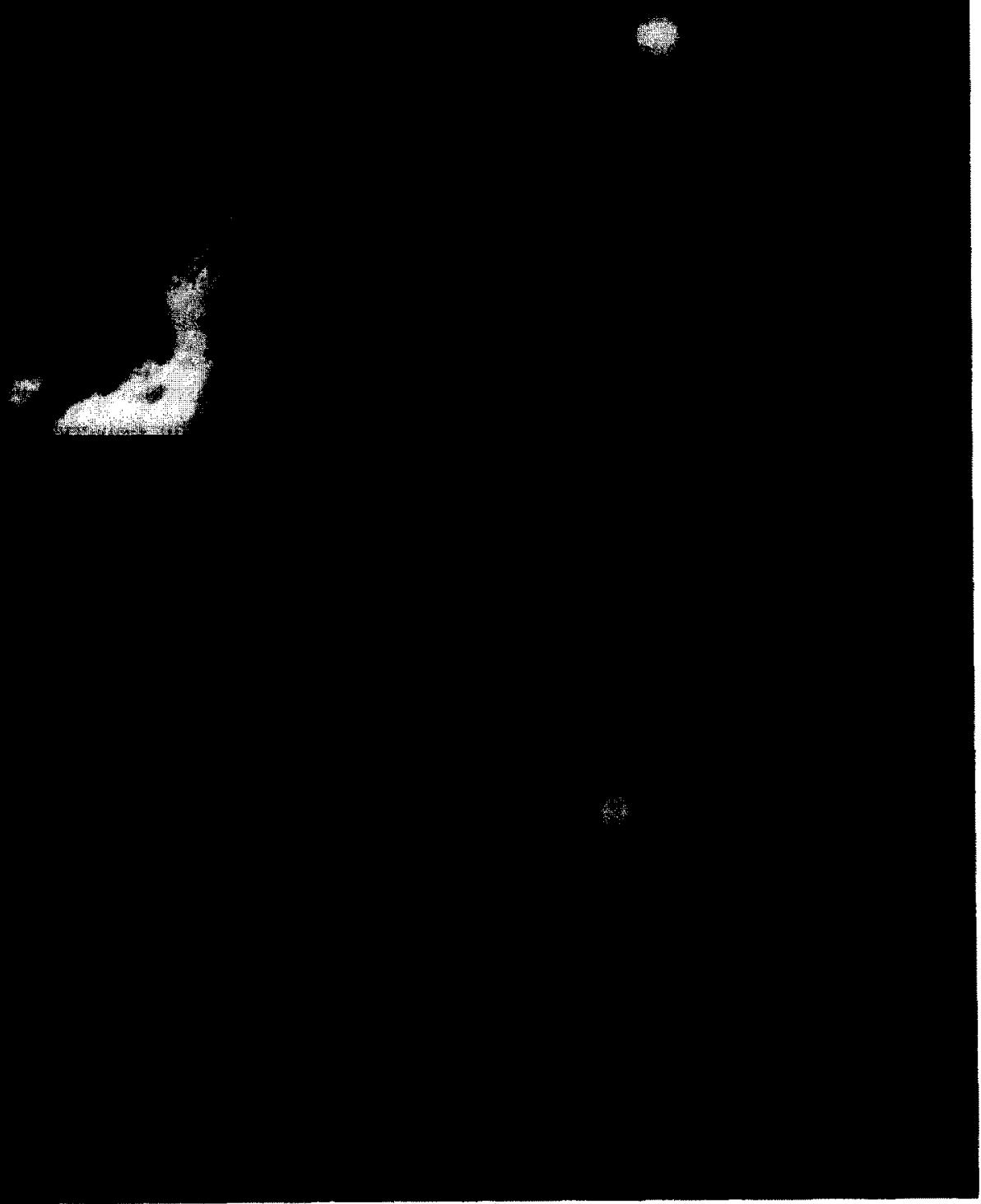

Fig. 3. Scanning transmission electron microscopy photographs and selected area electron diffraction (SAED) patterns of specimens prepared from thin sections of samples of the Wabash and Pride Mountain Formations. (a) Dark field image of a grain showing oxide-sulfide relations from the Wabash Formation. Hematite is identified along thin edge. (b) SAED pattern of the grain in Fig. 3a, diagnostic of hematite because of the 012, 104, 110, 202, 006, 116 and 214 reflections of hematite. The ring pattern of these reflections indicates the polycrystalline nature of the grain. (c) Dark field image of sub-micron size crystal showing oxide-sulfide relations from Pride Mountain Formation. The grain was part of the pseudoframboid shown in Fig. 2d. (d) SAED pattern of the grain in Fig. 3c, diagnostic of polycrystalline hematite based on hematite reflections of 012, 104, 110, 113, 024,116 and 214 . 
Although they were found only once in a thin section of the Wabash carbonates, pure iron oxide grains are of interest given the paleomagnetic characteristics (McCabe et al., 1985). A grain, about $2 \mu \mathrm{m}$ in size (Fig. 5a) with only $\mathrm{Fe}$ and $\mathrm{O}$ (Fig. 5b), was observed in a microcrack perched on top of an area containing flaky iron-rich clays (apparently chlorite, based on an EDS spectrum) among dolomite crystals. A small, but well-defined, contact boundary occurs between the grain and a dolomite crystal as seen in the SEM image (Fig. 5a). More grains of such pure iron oxide as seen in the thin section were obtained from magnetic extracts and have been identified as magnetite based on SAED patterns in STEM. A pure iron oxide grain from the Wabash Formation, about $1.5 \times 2 \mu \mathrm{m}$ in size (Fig. $5 \mathrm{c}$ ), has only $\mathrm{Fe}$ without Ti and/or S. A single-crystal SAED pattern of magnetite (Fig. Sd) obtained from a narrow band of bright area around the grain shown in the dark field image (Fig. 5c) confirmed the grain as a single-crystal magnetite. A pure iron oxide grain of $2 \mu \mathrm{m}$ in size (Fig. 5e) from mag- netic extracts of the Pride Mountain carbonate was identified as polycrystalline magnetite based on its SAED ring pattern (Fig. 5f). However, the domain state inferred from the grain sizes of such pure magnetite grains is most likely multidomain (MD), hence these magnetite grains are not likely to be the remanence carrier of the carbonates.

Euhedral octahedral crystals of pure iron oxide (Fig. 6a) were commonly observed in magnetic extracts. Such crystals range in size from 1 to $70 \mu \mathrm{m}$ and are inferred to be magnetite based on their crystal form and composition. The occurrence of growth features such as sharp crystal edges indicates a secondary origin.

Fe-Ti oxide grains (Fig. 6b) whose chemical composition are close to that of ilmenite or ferropseudobrookite were also found occasionally in the magnetic extracts. Well rounded surfaces are indicative of a detrital origin. The Fe-Ti oxide grain of Figure $6 \mathrm{~b}$ is the only one that we have seen as comparable to the titaniferous iron oxide grains with a high-temperature oxidation exsolution texture found by McCabe et al. (1989).

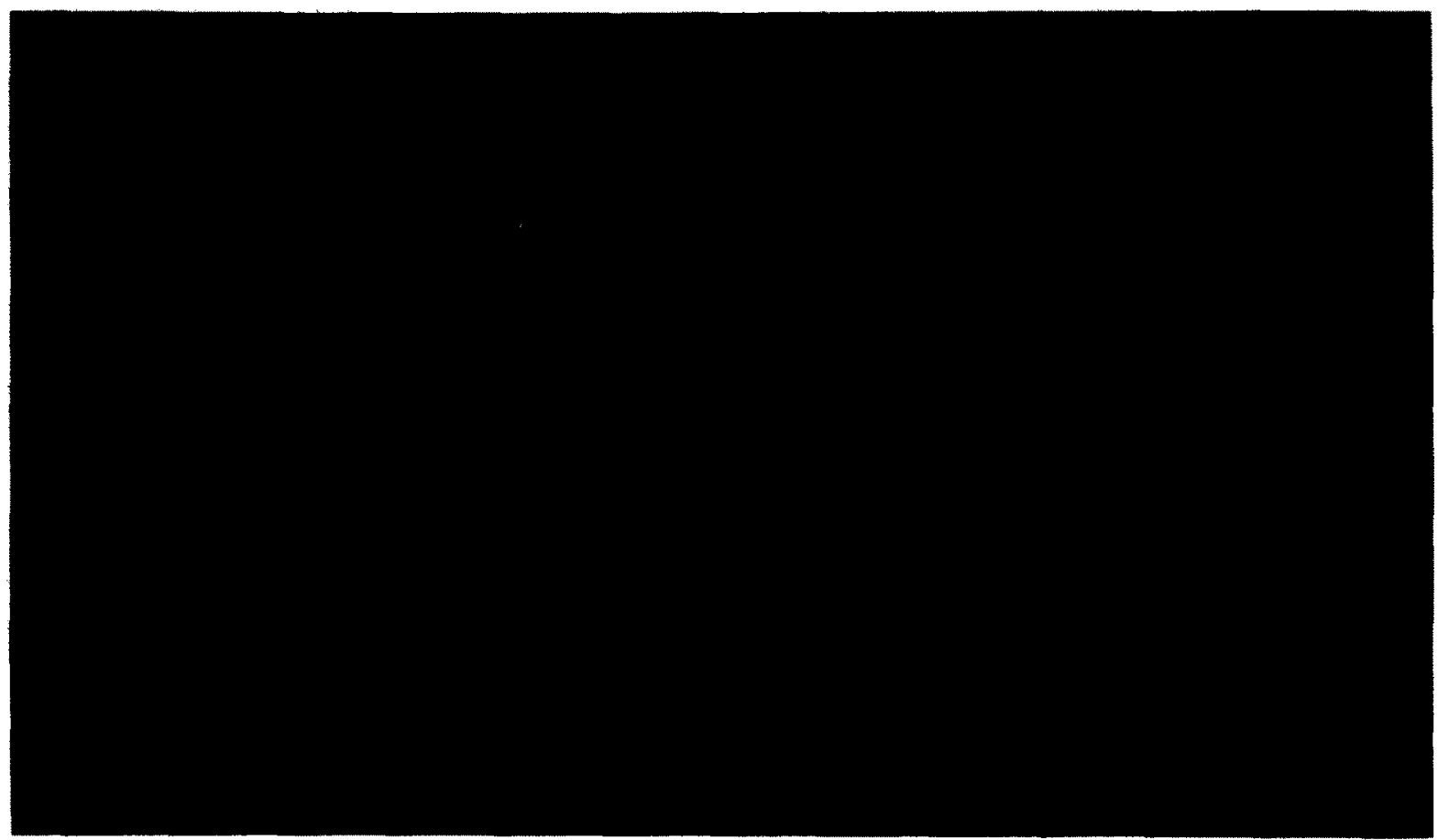

Fig. 4. Scanning electron microscopy photographs of magnetic extracts from the Wabash and Pride Mountain Formations. (a) Spherical magnetite identified by X-ray diffraction from the Pride Mountain Formation. (b) Pseudoframboid inferred to be hematite from the Wabash Formation. This pseudoframboid contains $S$ in addition to $F e$ and $O$. 


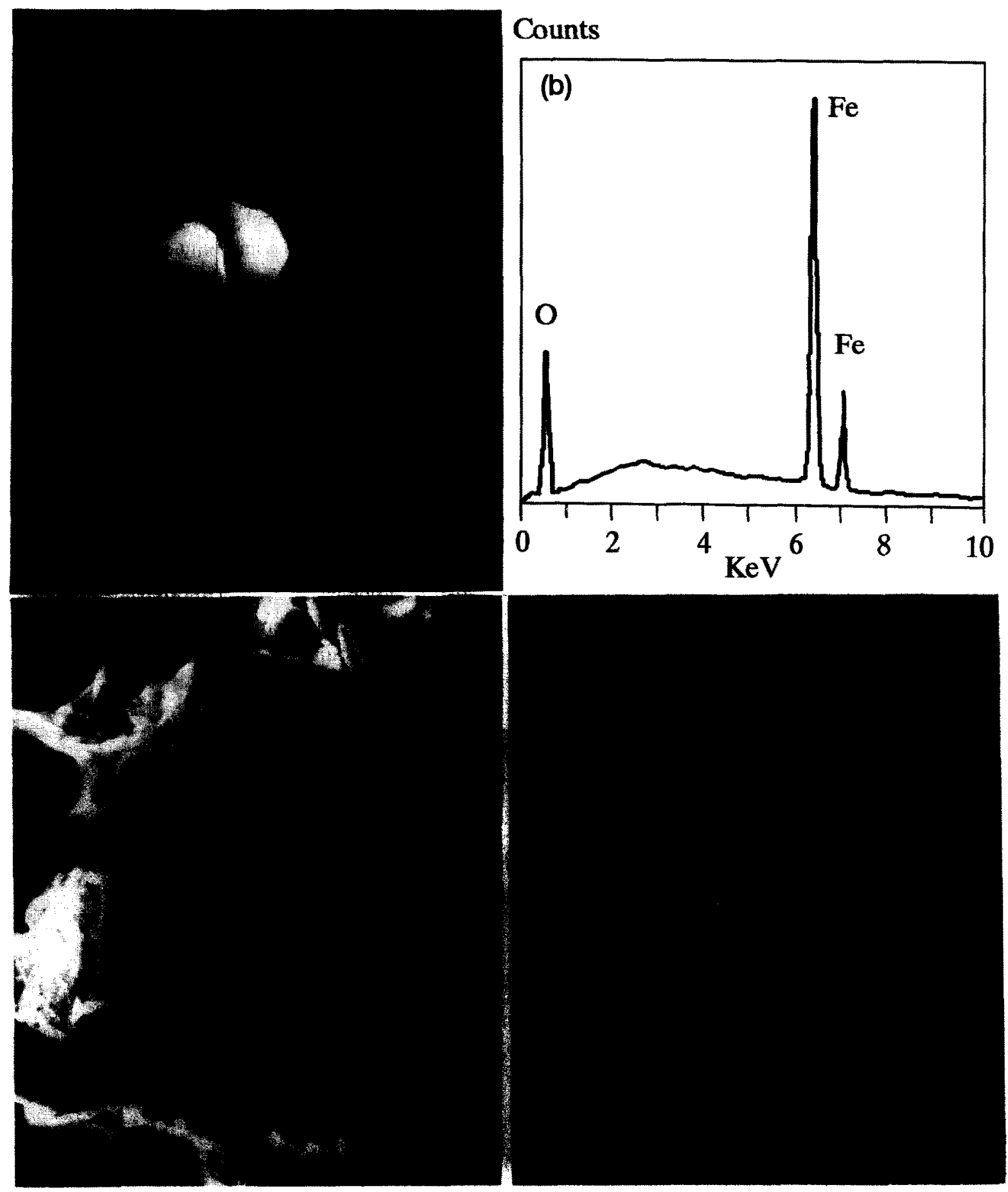

Fig. 5. Scanning and scanning transmission electron microscopy photographs and SAED patterns of magnetic extracts from the Wabash and Pride Mountain Formations. (a) SEM photograph of pure iron oxide grain sitting on top of chlorite (Ch) in microcracks. Wabash dolomite near the city of Wabash. (b) Energy-dispersive spectroscopic (EDS) spectrum from iron oxide shown in Fig. 5a. (c) Pure iron oxide grain about $2 \mu \mathrm{m}$ in size from the Wabash Formation. (d) SAED pattern of the grain in Fig. $5 \mathrm{c}$, diagnostic of a single crystal magnetite based on (220) and (422) reflections. Spot pattern is indicative of the single crystal nature of the grain. (e) A polycrystalline magnetite grain of about $2 \mu \mathrm{m}$ in size verified by SAED pattern, from the Pride Mountain Formation. (f) SAED pattern of the grain in Fig. Se, diagnostic of polycrystalline magnetite because of the ring pattern of 311 , 321 , 


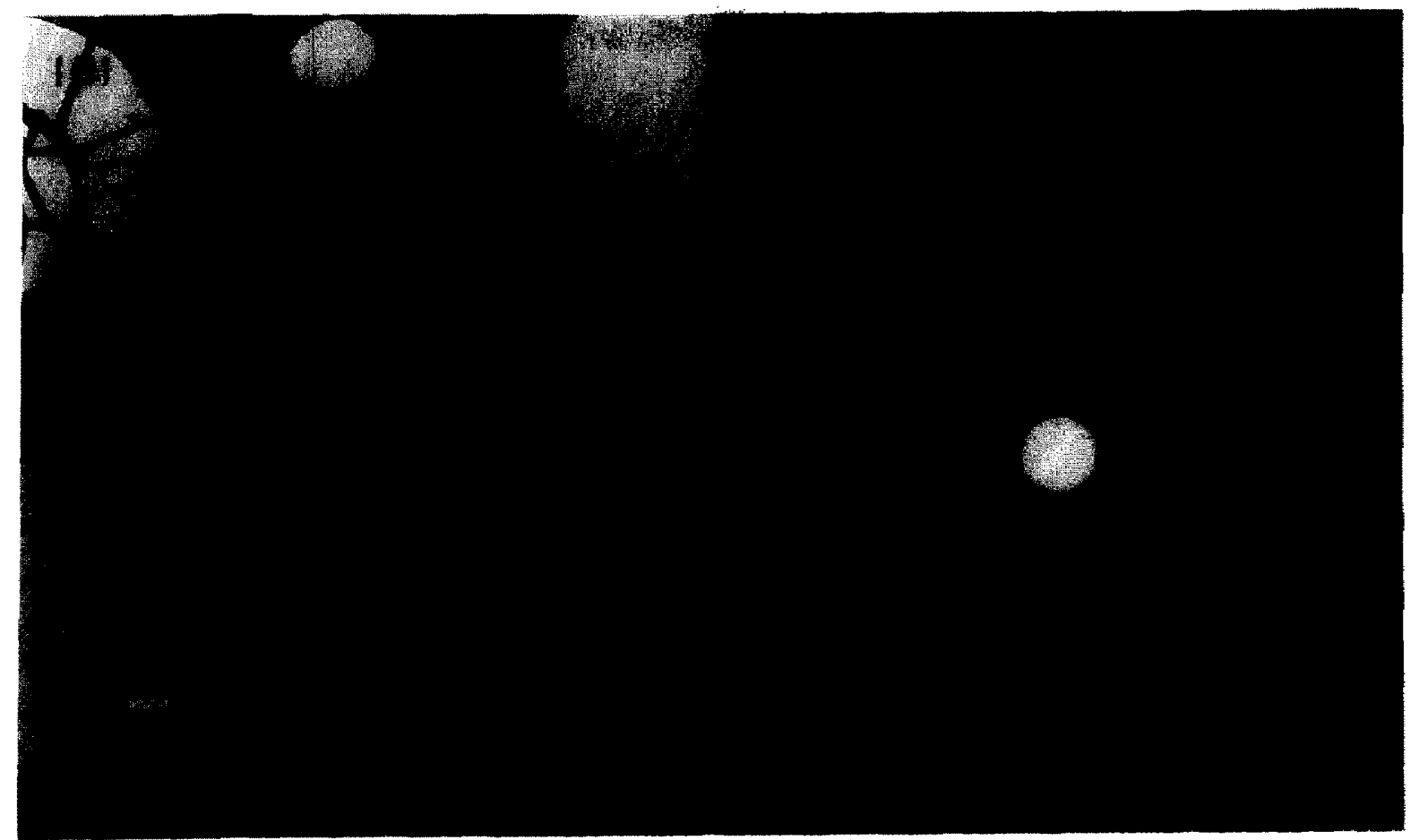

Fig. 5 (continued)

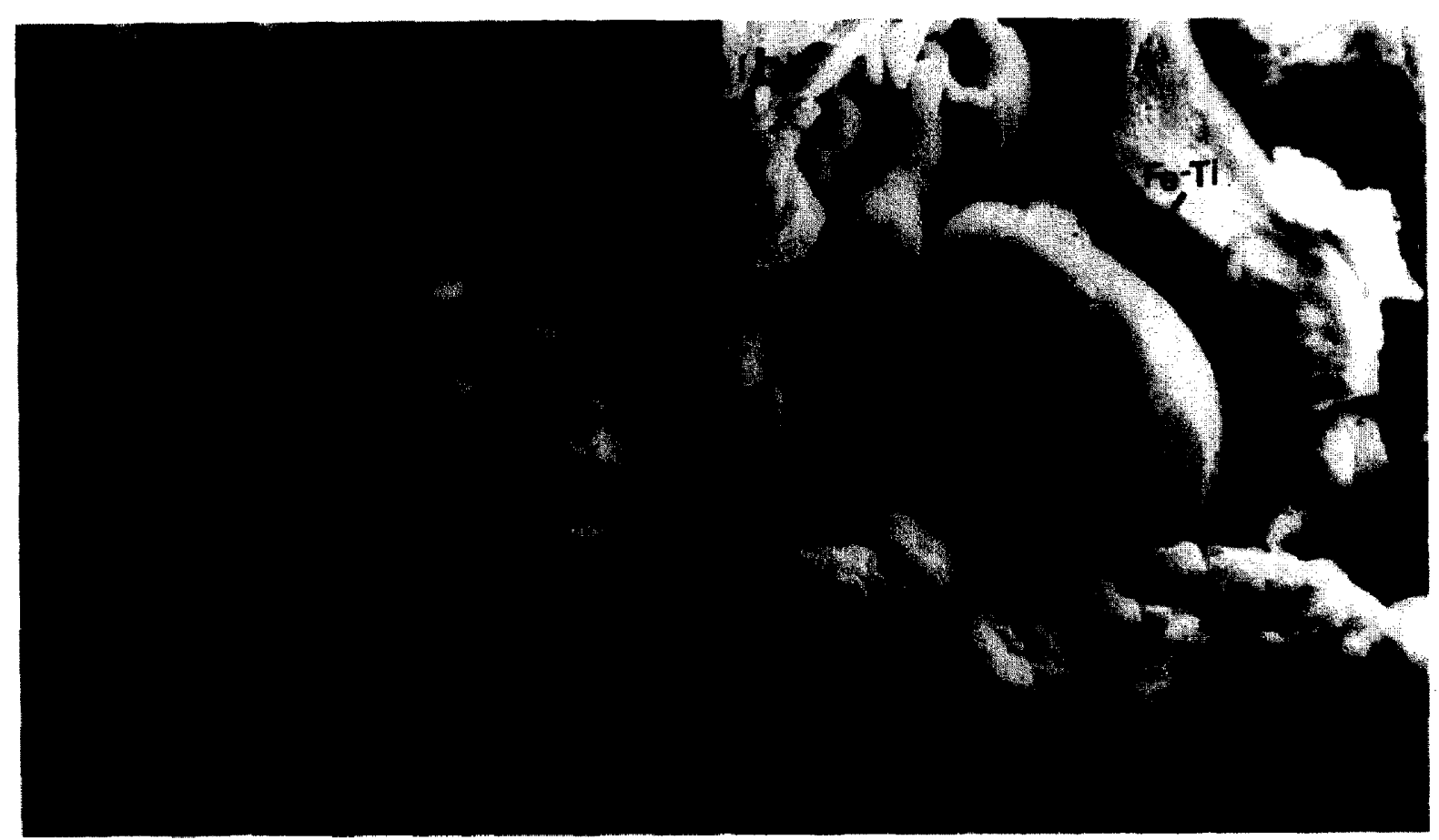

Fig. 6. Scanning electron microscopy photographs of magnetic extracts. (a) Euhedral pure iron oxide from the Pride Mountain Formation. Well-preserved octahedral form indicates a secondary (diagenetic) origin. (b) Fe-Ti oxide grain from the Wabash Formation with well-rounded surface indicates a detrital origin. 

These iron oxides observed in thin sections and in magnetic extracts, however, are not the remanence carrier of the carbonates because they do not appear to satisfy the single domain (SD) magnetite state inferred from the previous paleomagnetic studies (McCabe et al., 1985, 1989).

Aggregates of iron oxide crystals in the order of $0.5 \mu \mathrm{m}$ were located in the magnetic extracts from the Pride Mountain carbonate as shown in a secondary electron image (Fig. 7a). A few sets of superimposed single-crystal SAED patterns (Fig. $7 \mathrm{~b})$ taken from parts of the aggregates allowed us to interpret them as consisting of single crystals of magnetite. The grain size of individual singlecrystal magnetite was determined by a dark field image of the aggregates (Fig. $7 \mathrm{c}$ ) in which several grains in bright contrast of about $0.05 \mu \mathrm{m}$ in size gave rise to the observed SAED pattern. These single-crystal magnetite grains are in the SD to pseudo-single domain (PSD) size range. These magnetite grains are, therefore, capable of carrying the ancient remanence in these carbonates, although we have observed them only once.

\section{Rock magnetic properties}

Four representative samples of the unremagnetized carbonates were subjected to rock magnetic experiments. These were:

(1) a limestone sample of the Pride Mountain carbonate, Alabama (Alabama Limestone);

(2) a limestone sample from the Wabash Formation in the Pipe Creek Jr. Quarry (PCJ Limestone);

(3) a dolomitic mudstone of the Wabash Formation from the Pipe Creek Jr. Quarry (PCJ Dolomite); and

(4) a dolomite sample of the Wabash Formation from the railroad outcrop in the town of Wabash, Indiana (Wabash Dolomite).

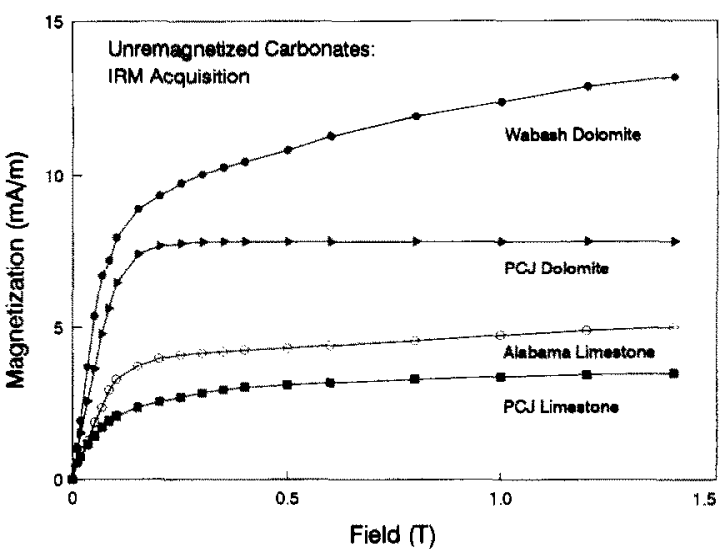

Fig. 8. IRM acquisition curves of samples from the Wabash and Pride Mountain Formations. Continuous increase in intensity in fields above $0.3 \mathrm{~T}$ indicates the presence of hematite. Rapid increases up to $0.15 \mathrm{~T}$ for all samples indicate the presence of magnetite.

Hereafter, the informal sample names given above in parentheses are used to describe magnetic behavior. In the IRM acquisition experiments, the presence of some hematite is clear for all samples except the PCJ Dolomite (Fig. 8). This agrees well with our STEM observations. However, in all cases, IRM is acquired rapidly up to $0.15 \mathrm{~T}$, suggesting that magnetite is predominant. IRM for the PCJ Dolomite reached a saturation value well below $0.3 \mathrm{~T}$, revealing a typical IRM acquisition curve of magnetite. This does not necessarily rule out the presence of hematite in the specimen; the absence of a high-coercivity portion in the specimen means only that there is no evidence for hematite.

Although intensities of ARM for each of the 5-mT windows were very weak (typically in the order of $10^{-5} \mathrm{~A} / \mathrm{m}$ ), the pARM measurements yielded reasonably well defined pARM curves (Fig. 9). The most abundant coercivities in these samples are between 20 and $30 \mathrm{mT}$, which corresponds to magnetite grains of 2-3 $\mu \mathrm{m}$-size (Marvin et al., 1986). The ARM of the weakest

Fig. 7. Scanning transmission electron microscopy photographs and SAED pattern of magnetic extracts. (a) An aggregate of magnetite grains found in the Pride Mountain Formation, secondary electron image (SEI) in TEM mode. (b) SAED pattern of the aggregate in Fig. 7 a, diagnostic of single crystal magnetite based on (111), (311), and (220) reflections. (c) Dark field image of the aggregate in Fig. 7a; bright spots are the areas giving rise to the SAED pattern in Fig. $7 \mathrm{~b}$. Sizes of bright spots reflect sizes of individual grains in the aggregate. 


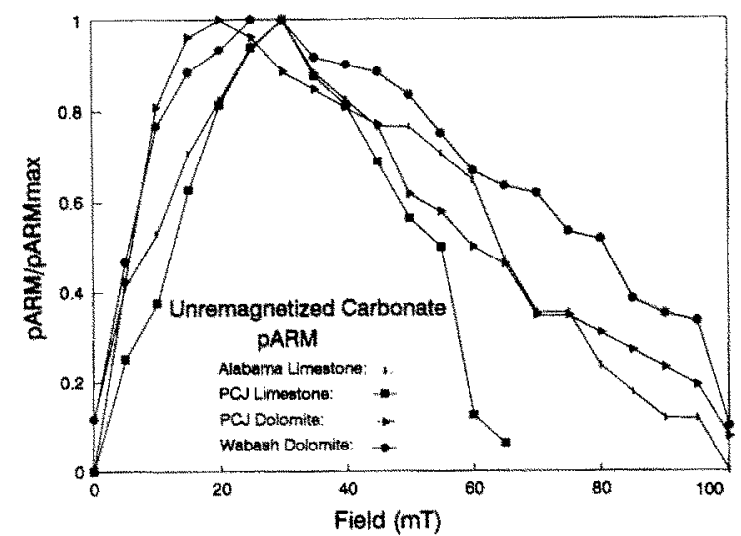

Fig. 9. pARM curves of samples from the Wabash and Pride Mountain Formations. The most abundant coercivities are $20-30 \mathrm{mT}$, corresponding to magnetite grains of $2-3 \mu \mathrm{m}$ size.

specimen, PCJ Limestone, becomes unobservable above $60 \mathrm{mT}$, while tails in a higher coercivity portion persist for the rest of samples (Fig. 9). However, hematite identified by the IRM acquisition curves in the specimens did not appear to contribute to the pARM curves as the typical coercivity of hematite is far above the peak AF value.

The modified Lowrie-Fuller test (Lowrie and Fuller, 1971; Johnson et al., 1975) showed that the ARM is more stable than IRM against AF demagnetization for all samples below $60 \mathrm{mT}$, yielding a SD or PSD test result (Fig. 10). More importantly, the inflected shape of decay curves, rather than the configuration of ARM and IRM decay curves, is evidence for a considerable contribution by SD and PSD grains (Dunlop, 1983). Nevertheless, the relatively steep decay rate in IRM curves at a low alternating field is an indication of additional coarse-grained multidomain (MD) magnetite (Dunlop et al., 1973), such as the 2-3 $\mu \mathrm{m}$-size grains inferred from the pARM curves and observed by SEM/STEM. As in the pARM experiments, a contribution from hematite is not recognized in the modified Lowrie-Fuller test. Figure 11 shows results of the Cisowski test which is expected to reveal interactions among fine grained magnetic minerals. The $R$ values, i.e., values of the intersection points of IRM acquisition and demagnetization curves projected

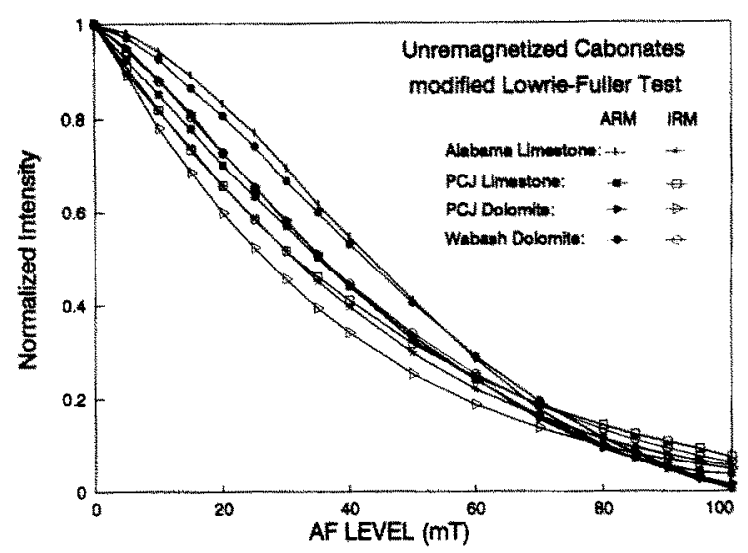

Fig. 10. Stabilities of isothermal remanent magnetization (IRM) and anhysteretic remanent magnetization (ARM) against alternating field (AF) demagnetization (modified Lowrie-Fuller test, Lowrie and Fuller, 1971; Johnson et al, 1975), showing SD/PSD behavior in samples from the Wabash and Pride Mountain Formations.

on the vertical axis, are in the range of $0.41-0.49$ (Fig. 11); this is in good agreement with values for non-interacting SD particles (Cisowski, 1981). The presence of hematite is detected only by the SIRM acquisition experiment. However, the pARM, modified Lowrie-Fuller and Cisowski tests collectively indicate a combination of noninteracting SD magnetite behavior and multidomain $2-3 \mu \mathrm{m}$-sized magnetite grains in our specimens.

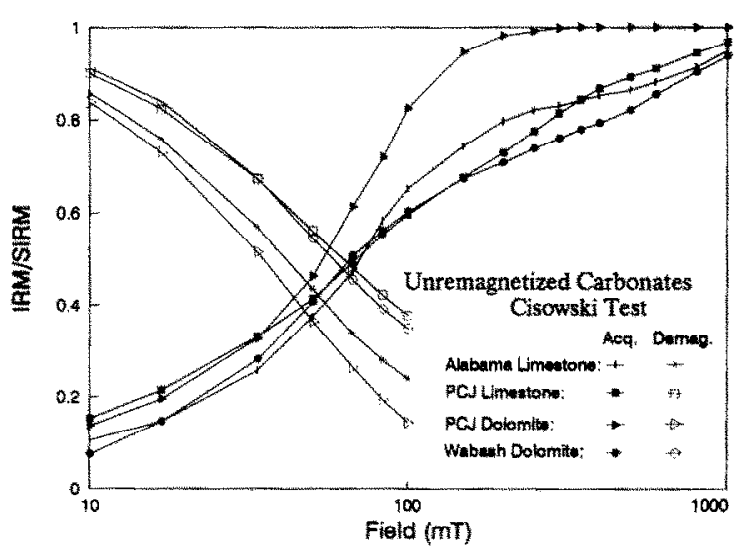

Fig. 11. IRM acquisition and AF demagnetization curves for samples of the Wabash and Pride Mountain Formations, indicating remanence carried by non-interacting fine particles, according to the test of Cisowski (1981). 


\section{Discussion}

Paleomagnetic directions of the two studied carbonates are different from each other as well as from those in remagnetized carbonates in the northeastern part of U.S.A., which have been revealed to carry a uniformly reversed late Paleozoic Kiaman direction (Kent, 1979; McCabe et al., 1983, 1984; Scotese et al., 1982; Bachtadse et al., 1987; Jackson et al., 1988). In contrast, the unremagnetized carbonates have been inferred to have paleomagnetic directions of depositional age. The latter contain normal and reversed polarities and show no evidence for a later Paleozoic direction (McCabe et al., 1985, 1989; Jackson and Van der Voo, 1985). Stronger remanence intensities of the remagnetized carbonates than in unremagnetized carbonates may well be a criterion for remagnetization in carbonate rocks (e.g., $\mathrm{Lu}$ et al., 1990), reflecting higher concentrations of magnetic minerals. Late formation of abundant new magnetic minerals in remagnetized carbonates is clearly the cause. On the other hand, the carriers of remanence in both unremagnetized and remagnetized carbonates have been inferred to be SD to PSD magnetite with unblocking temperatures of about $500^{\circ} \mathrm{C}$; thus size alone is not a distinguishing factor or criterion and we must look further at the available data regarding composition, texture, shape, magnetic domain state and species of magnetic minerals.

It has come as a considerable surprise to us that iron oxides, detected by SEM in the unremagnetized carbonates are, at first glance, very similar to those found in remagnetized carbonates as in both cases iron oxides are associated with iron sulfides (see Suk et al., 1990b). However, detailed SEM/STEM observations defined both similarities and differences in magnetic minerals in unremagnetized and remagnetized carbonates as outlined in Table 1. In the following sections, the similarities and differences are discussed based on the SEM/STEM observations made in this study and in our previous studies.

\section{Grains with sulfur}

The most abundant iron oxide grains observed in thin sections by SEM are those revealing iron oxide-sulfide relations either in grains with an irregular shape (Fig. 2a) or in the form of pseudoframboids (Figs. $2 \mathrm{~d}, 4 \mathrm{~b}$ ). These grain types are similar, at the SEM level of observations, to those found in remagnetized carbonates (Suk et al., 1990b; Lu et al., 1990), except that many grains

\section{TABLE 1}

Similarities and differences between remagnetized and unremagnetized carbonates

\begin{tabular}{|c|c|c|c|}
\hline \multirow[t]{2}{*}{ Similarity } & \multicolumn{3}{|l|}{ Difference } \\
\hline & Category & Remagnetized rocks & Unremagnetized rocks \\
\hline \multicolumn{4}{|l|}{ Magnetic mineralogy } \\
\hline Oxide-sulfide relations & Sulfides associated: & Replaced by magnetite & Replaced by hematite \\
\hline $\begin{array}{l}\text { Many spherical magnetite } \\
\text { grains }\end{array}$ & Pure euhedral iron oxide: & Absent & Present \\
\hline Occasional occurrence of & Fine-grained magnetite: & Abundant & Rare \\
\hline \multicolumn{4}{|l|}{ Paleo- and rock magnetism } \\
\hline \multirow{4}{*}{$\begin{array}{l}\text { Remanence carrier: } \\
\text { SD to PSD magnetite } \\
\text { Unblocking temperature: } \\
\text { about } 500^{\circ} \mathrm{C}\end{array}$} & Paleomagnetic direction: & $\begin{array}{l}\text { late Paleozoic Kiaman } \\
\text { direction }\end{array}$ & $\begin{array}{l}\text { Primary direction of } \\
\text { depositional age. }\end{array}$ \\
\hline & & & $\begin{array}{l}\text { No evidence for later } \\
\text { Paleozoic direction }\end{array}$ \\
\hline & intensity of remanence: & Strong & Weak \\
\hline & $\begin{array}{l}\text { (Concentration of mag- } \\
\text { netic minerals): }\end{array}$ & (High) & (Low) \\
\hline
\end{tabular}


were verified to be hematite (Fig. 3) in the unremagnetized carbonates, whereas they are exclusively magnetite in the remagnetized rocks. Iron oxides (hematite or magnetite) associated with iron sulfide have been shown to be a replacement of pyrite by oxidation in the unremagnetized carbonates (Figs. 3a, c) as well as the remagnetized carbonates (Suk et al., 1990b; Lu et al, 1990). Thus pseudoframboids and irregularly shaped grains display a wide range of iron sulfide/iron oxide proportions in both remagnetized and unremagnetized carbonates, the only difference being that unremagnetized rocks contain iron oxide as hematite.

Magnetic extracts of the unremagnetized carbonates for this study appear to contain as many iron oxide spherules as the remagnetized carbonates (Suk et al., 1992). More than $75 \%$ of spherical iron oxide grains observed in magnetic extracts are pure magnetite (e.g., Fig. 4a), whereas the rest of the spherules are pseudoframboids which contain some sulfide; some of these spheres have been shown to contain hematite (Fig. $3 \mathrm{c}$ and perhaps Fig. 4b). Although, of course, not all of the latter grains imaged by SEM in this study could be characterized by SAED, we feel confident that most iron oxide grains are hematite if they show morphologies and textures similar to those that were examined by the SAED method (e.g., Fig. 3c). The relative abundance of spherical magnetite and hematite pseudoframboids with $S$ in magnetic extracts of the unremagnetized carbonates conflicts with the fact that spherical magnetite was not observed in thin sections. The greater abundance of spherical magnetite grains in the magnetic extracts, however, can be explained by the fact that magnetite spherules may be preferentially extracted over hematite pseudoframboids during the magnetic separation process because magnetite is much stronger magnetically than hematite. Magnetite spherules found in the unremagnetized carbonates are similar to those found in the remagnetized carbonates in morphology and texture, but their origin (e.g., whether they are products of replacement of pyrite) is not clearly known. As such, magnetite spherules in the remagnetized carbonates have not been proven to be a carrier of the remagneti- zation, although it was suggested that they are one of the most plausible magnetic carriers in the carbonates (Suk et al., 1992). The presence of spherical magnetite grains in all studied carbonates only implies that their presence is no longer sufficient evidence for a late remagnetization. On the other hand, the presence of hematite as a replacement of pyrite in unremagnetized carbonates is one of the more obvious differences from the remagnetized carbonates, in which magnetite replaces pyrite, with hematite observed very rarely (Suk et al., 1990b; Lu et al., 1990). However, because hematite has not been identified as a primary magnetic carrier either in the Wabash Formation (McCabe et al. 1985) or in the Mississippian Pride Mountain Formation (McCabe et al., 1989) in paleomagnetic studies, a hematite contribution to the remanence, if any, is inferred to be much smaller than that of the intrinsically much more strongly magnetic grains of magnetite. Therefore, using the presence of hematite to distinguish unremagnetized rocks from remagnetized carbonates is impractical because hematite is not the carrier of the remanence. The STEM observations of hematite in samples of the Wabash and Pride Mountain Formations have been confirmed by the SIRM acquisition experiments. However, hematite does not appear to contribute significantly to the pARM, and has not been detected by modified Lowrie-Fuller and Cisowski tests. This probably indicates that the hematite in these carbonates has coercivities higher than the maximum induction field of 100 $\mathrm{mT}$; ARM and IRM imparted by AF and DC fields up to $100 \mathrm{mT}$ were almost completely erased by AF demagnetization of $100 \mathrm{mT}$ (Fig. 9).

The grain sizes of the hematite seen to replace pyrite (Figs. 3a and 3c) are less than $0.1 \mu \mathrm{m}$. Hematite of this size may be either in the SD or in the superparamagnetic (SP) state depending on a choice of SP threshold size. The SP threshold size for hematite, at which the transition from unstable SP behavior to the extremely stable SD state occurs, has been reported at $0.1 \mu \mathrm{m}$ (Chevallier, 1951; Strangway et al., 1968) but it may be extended up to $0.3 \mu \mathrm{m}$ (Hedley, 1968) or down to 0.025-0.03 $\mu \mathrm{m}$ (Bando et al., 1965; Banerjee, 1971). If the hematite grains behave as 
SP particles in the carbonates of this study, they do not contribute to the remanence, but this leaves the high (hematite?) coercivities of the IRM acquisition experiment unexplained. Wc conclude, therefore, that hematite must be in the SD state.

For non-interacting, randomly distributed, uniaxial hematite grains, theoretical evaluation of chemical remanent magnetization (CRM) based on Néel theory predicts quasi-linear dependence of CRM intensity on the applied field (e.g., Stacey and Banerjee, 1974). If authigenic hematite grains are in the SD state, a remanent magnetization of a CRM origin is expected. No contribution by hematite to remanences in samples of the Wabash and Pride Mountain Formations has been recognized in paleomagnetic studies (McCabe et al., $1985,1989)$. The only plausible explanation that remains is that the assemblage of hematite grains, as replacements of pyrite, is randomly distributed but interacting. Under this special condition, a CRM acquired by a growing hematite grain would not have a systematic direction of magnetization and the contributions from several grains may thus add up to a negligible resultant moment.

\section{Euhedral larger grains}

The occurrence of abundant euhedral pure magnetite crystals (Fig. 6a) in the unremagnetized carbonates contrasts with their absence in the remagnetized carbonates from eastern North America (Suk et al., 1990a,b). The sharp, euhedral (octahedral) forms imply that they are authigenic. In a recent study, however, euhedral iron oxide grains of similar shape were observed in magnetic extracts of the Jurassic Twin Creek Limestones from the Idaho-Wyoming Overthrust Belt (Xu, pers. commun., 1992) that were remagnetized in the Tertiary (McWhinnie et al., 1990). Nevertheless, such large magnetite grains cannot be carriers of an ancient (primary or secondary) remanence in the carbonates because the multidomain state inferred from their grain size is incompatible with the characteristics of the remanence carriers. Thus, the presence of the euhedral iron oxides cannot be used as a diagnostic criterion of the unremagnetized rocks.

\section{Submicron magnetite}

We find it is more plausible that small mag. netite grains, such as those of a cluster of single crystal magnetite grains, about $0.05 \mu \mathrm{m}$ in size (Figs. 7a,c), are the possible remanence carrier in the carbonates, although the fact that we have observed their occurrence infrequently makes the conclusion that they are the carriers of an early (primary?) remanence tentative at best. The clustering of the fine-grained magnetite is due to magnetic attraction between magnetic grains during the extraction process. These fine-grained magnetite crystals not only fit the size range of SD and PSD magnetite (e.g., Dunlop, 1973) but also satisfy the magnetic behavior of non-interacting SD to PSD magnetite shown by the rock magnetic experiments in the samples. The occurrence of the fine-grained magnetite grains in unremagnetized carbonates is rare; fine-grained single-crystal magnetite grains of about $2000 \AA$ (200 $\mathrm{nm}$ ) in size (Suk et al., 1992), which are similar to those found in the unremagnetized carbonates, are abundant in the remagnetized carbonates. It may be argued that the rare occurrence of these fine-grained magnetite grains in the unremagnetized carbonates degrades the probability of the grains as the carriers of the primary magnetization in the carbonates. However, the differences in abundance of such fine-grained magnetite in remagnetized versus unremagnetized carbonates can explain the strong versus weak intensity of ancient magnetization in the two carbonate types. Therefore, it is suggested that the difference in the abundance of the fine-grained magnetite grains is a diagnostic factor to distinguish unremagnetized carbonates from remagnetized rocks. Be that as it may, this clarifies only the carriers in the remagnetized carbonates and leaves the question of the carriers in unremagnetized limestones unresolved to a large extent, because it remains unproven that these submicron grains are primary rather than authigenic in the unremagnetized carbonates.

\section{Other iron oxides}

Non-spherical magnetite has also been identified in magnetic extracts by SAED (Figs. 5c-f). 
Much of it occurs as polycrystalline or singlecrystal grains of about $2-3 \mu \mathrm{m}$ in size. These magnetite grains observed in magnetic extracts are also seen in thin sections (Fig. 5a); these observations are compatible with our conclusions from pARM experiments, which show that the most significant fraction of magnetite is $2-3 \mu \mathrm{m}$ in size (Fig. 9). They are not, however, likely to be the carriers of the characteristic remanence because of their inferred MD state.

Unlike McCabe et al. (1989), we were unable to locate either in thin sections or in the magnetic extracts any titaniferous magnetite showing hightemperature oxidation exsolution textures. Instead, homogeneous Fe-Ti oxide grains (Fig. 6b) with well-rounded surface and a composition close to that of ilmenite or ferropseudobrookite were found in the magnetic extracts. Although their morphologies are indicative of a detrital origin, their composition implies that they are paramagnetic at room temperature, hence they are not carriers of magnetization in the carbonates. Obviously, titaniferous magnctites with high-temperature oxidation exsolution textures must have been igneous in origin, but they are not necessarily carriers of the primary magnetization in the carbonates. Some Fe-Ti oxides occur in both remagnetized and unremagnetized carbonates (Fig. 6b; McCabe et al., 1989; Suk et al., 1990a).

\section{What lets rocks escape remagnetization?}

Fluid-mediated reaction in the remagnetized carbonates in the northeastern U.S.A. is now a generally accepted process for the formation of authigenic magnetite (McCabe et al., 1989; Lu et al., 1990; Suk et al., 1990b, 1992). For the Pride Mountain carbonates in Alabama, McCabe et al. (1989) hypothesized that the impermeable Chattanooga Shalc horizon between the Pride Mountain carbonate and the underlying older carbonates played an important role protecting the Pride Mountain carbonates from rock-fluid interactions and, hence, remagnetization.

The Wabash reef in the Pipe Creek Jr. quarry is one of the two largest known limestone reefs in Indiana (Shaver and Sundermann, 1982) and is one of the best exposed (Ault and Carr, 1981).
Lehmann (1978) suggested that the early cementation of the Wabash reef limestone, and the resultant loss in porosity and permeability of the reef rock, may in part explain the lack of dolomitization of most of the Pipe Creek Jr. reef. In addition, Sundermann (1980) proposed that the cementation of the reef took place early, while still in the marine realm because no evidence of fresh-water vadose cementation of the reef sediments has yet been found.

These varied lines of evidence imply that only a very limited quantity of fluid may have been introduced into the Wabash Formation after deposition of sediments. If true, it is possible that the fine-grained magnetite grains inferred to be the carrier of the primary magnetization could have been preserved since the formation of the carbonates. However, even if the carbonates have escaped the late Paleozoic remagnetization event to some degree, the presence of clearly authigenic magnetite and hematite (formed after pyrite), indicates that the iron oxides are not all primary and that some diagenesis and/or later oxidation took place. It can also be speculated that this environment may in part provide the rather special conditions under which hematite grains have been growing at a very slow rate, such that no systematic remanence was acquired.

\section{Conclusion}

In summary, several differences in magnetic mineralogy between remagnetized and unremagnetized carbonates are recognized (see Table 1).

(1) Iron oxides associated with sulfides are verified to be hematite in the unremagnetized carbonates, whereas they are magnetite in the remagnetized carbonates.

(2) Common occurrences of euhedral pure iron oxide grains in the unremagnetized carbonates are distinctive.

(3) Fine-grained (submicron) single-crystal magnetite grains capable of carrying the remanence are found in both remagnetized and unremagnetized carbonates, but they are rare in the unremagnetized carbonates and abundant in the remagnetized carbonates.

It has been determined, based on the 
SEM/STEM observations of iron oxides in remagnetized and unremagnetized carbonates in this study and in our previous studies, that finegrained magnetite and possibly magnetite as a replacement of pyrite are the carriers of the remanence in remagnetized carbonates and that fine-grained magnetite grains are inferred to be the possible magnetic carrier in the unremagnetized carbonates, although it remains unproven that these submicrometer grains are primary rather than authigenic. The relative abundance of such fine-grained magnetite in remagnetized and unremagnetized carbonates is a criterion by which to distinguish them.

We attribute the lack of remagnetization to a restricted amount of fluid influx into the Wabash and the Pride Mountain Formations due to early cementation that has significantly reduced the porosity and permeability in the Wabash Formation in Indiana, and due to the presence of the impermeable Chattanooga Shale in the Mississippian Pride Mountain Formation in Alabama.

\section{Acknowledgements}

This study was supported by the Division of Earth Sciences, the National Science Foundation, grant EAR 89-15709 (to R.V.d.V. and D.R.P.). D.S. is grateful to Chad McCabe for providing Alabama carbonate rocks for this study.

\section{References}

Ault, C.H. and Car, D.D., 1981. Search for high-calcium limestone in Silurian reefs of northern Indiana. Geol. Soc. Axn. Bull, 92: 641-647.

Bachtadse, V., Van der Voo, R., Haynes, F.M. and Kesler, S.E., 1987. Late Paleozoic magnetization of mineralized and unmineralized Ordovician carbonates from East Tennessee: Evidence for a post-ore chemical event. J. Geophys. Res., 92: 14,165-12,176.

Bando, Y., Kiyama, M., Yamamoto, N., Takata, T., Shinjo, T. and Takaki $\mathrm{H}$, 1965. Magnetic properties of $\alpha-\mathrm{Fe}_{2} \mathrm{O}_{3}$ fine particles. J. Phys. Soc. Jpn., 20: 2086.

Banerjee, S.K., 1971. New grain size limits for paleomagnetic stability in hematite. Nature (London), Phys. Sci, 232: $15-16$.

Chevallier, R., 1951. Proprietes magnetiques de l'oxyde ferrique rhomboedrique $\left(\mathrm{Fe}_{2} \mathrm{O}_{3}-\alpha\right)$. J. Phys. Radium, 12: $178-188$.
Cisowski, C., 1981. Interacting vs. non-interacting single domain hehavior in natural and synthetic samples. Phys. Earth Planet. Inter., 26: 56-62.

Devaney, K.A., Wilkinson, B.H. and Van der Voo, R., 1986. Deposition and compaction of carbonate clinothems: The Silurian Pipe Creek Junior complex of east-central Indiana. Geol. Soc. Am. Bull., 97: 1367-1381.

Dorobek, S., 1989. Migration of orogenic fluids through the Siluro-Devonian Helderberg Group during late Paleozoic deformation: Constraints on fluid sources and implications for thermal histories of sedimentary basins. Tectonophysics, 159: $24-45$.

Dunlop, D.J., 1973. Superparamagnetic and single-domain threshold sizes in magnetite. J. Geophys. Res., 78: 17801793.

Dunlop, D.J., 1983. Determination of domain structure in igneous rocks by alternating field and other methods. Earth Planet. Sci. Lett., 63: 353-367.

Dunlop, D.J., Hanes, J.A. and Buchan, K.L., 1973. Indices of multidomain magnetic behavior in basic igneous rocks: Alternating-field demagnetization, hysteresis, and oxide petrology. J. Geophys. Res., 78: 1387-1393.

Hedley, I.G., 1968. Chemical remanent magnetization of the $\mathrm{FeOOH}, \mathrm{Fe}_{2} \mathrm{O}_{3}$ system. Phys. Earth Planet. Inter., 1: 103-121.

Jackson, M., 1990. Diagenetic sources of stable remanence in remagnetized Paleozoic cratonic carbonates: A rock mag netic study. J. Geophys. Res., 95: 2753-2761.

Jackson, M. and Van der Voo, R., 1985. A lower Ordovician paleomagnetic pole from the Oneota dolomite, upper Mississippi River Valley. J. Geophys. Res, 90: 10,449-10,461.

Jackson, M., McCabe, C., Ballard, M.M. and Van der Voo, R., 1988. Magnetite authigenesis and diagenetic paleotemperatures across the northern Appalachian basin. Geology, 16: $592-595$.

Johnson, H.P., Lowrie, W. and Kent, D.V., 1975, Stability of anhysteretic remanent magnetization in fine and coarse magnetite and maghemite particles. Geophys. J.R. Astron. Soc., $41: 1-10$.

Kent, D.V., 1979. Paleomagnetism of the Devonian Onondaga limestones revisited. J. Geophys. Res, 84: 3576-3588.

Kent, D.V., 1985. Thermoviscous remagnctization in some Appalachian limestones. Geophys. Res. Lett., 12: 805 -808.

Lehmann, P.J, 1978. Deposition, porosity evolution and diagenesis of the Pipe Creek Jr. reef (Silurian), Grant County, Indiana. M.S. thesis, University of Wisconsin, Madison, $234 \mathrm{pp}$.

Lowrie, W. and Fulter, M., 1971. On the alternating field demagnetization characteristics of multidomain thermoremanent magnetization in magnetite. J. Geophys. Res., 76: $6339-6349$.

Lu, G. and McCabe, C., 1991. Regional pattern of remagnetization on the Nashville and Jessamine Domes (Tennessee and Kentucky) (abstract). Eos, 72: 100-101.

Lu, G., Marshak, S. and Kent, D.V., 1990. Characteristics of magnetic carriers responsible for Late Paleozoic remagne- 
tization in carbonate strata of the mid-continent, U.S.A. Earth Planct. Sci. Lett., 99: 351-361.

Marvin, J., Gruber, W., Kelso, P. and Banerjee, S.K., 1986. pARM: A rock magnetic method for recognition of mixed grainsize magnetic materials (abstract). Eos, 67: 927.

McCabe, C. and Elmore, R.D., 1989. The occurrence and origin of Late Palcozoic remagnetization in the sedimentary rocks of North America. Rev. Geophys., 27: 471-494.

McCabe, C., Van der Voo, R., Peacor, D.R., Scotese, C.R. and Freeman, R., 1983. Diagenetic magnetite carries ancient yet secondary remanence in some Paleozoic sedimentary carbonates. Gcology, 11: 221-223.

McCabe, C., Van der Voo, R. and Ballard, M.M., 1984. Late Paleozoic remagnetization of the Trenton limestone. Geophys. Res. Lett., 11: 979-982.

McCabe, C., Van der Voo, R., Wilkinson, B.H. and Devaney, K., 1985. A middle/late Silurian palcomagnctic polc from limestone reefs of the Wabash Formation, Indiana, U.S.A. J. Geophys. Res., 90: 2959-2965.

McCabe, C., Jackson, M. and Saffer, B., 1989. Regional patterns of magnetite authigenesis in the Appalachian Basin: Implications for the mechanism of Latc Palcozoic remagnetization. J. Geophys. Res., 94: 10,429-10,443.

McElhinny, M.W. and Opdyke, N.D., 1973. Remagnetization hypothesis discounted: A paleomagnetic study of the Trenton Limestone, New York State. Geol. Soc. Am. Bull., 84: 3697-3708.

McWhinnie, S.T., van der Pluijm, B.A. and Van der Voo, R., 1990. Remagnetizations and thrusting in the IdahoWyoming Overthrust Belt. J. Geophys. Res., 95: 45514559.

Miller, J.D. and Kent, D.V., 1988. Regional trends in the timing of Alleghenian remagnetization in the Appalachians. Geology, 16: 588-591.

Scotese, C.R., Van der Voo R. and McCabe, C., 1982. Paleomagnetism of the Upper Silurian and Lower Devonian carbonates of New York State: Evidence for secondary magnetizations residing in magnetite. Phys. Earth Planet. Inter., 30: 385-395.

Shaver, R.H. and Sunderman, J.A., 1982. Silurian reefs at Delphi and Pipe Creek Junior quarry, Indiana, with emphasis on the question of deep vs. shallow water. Purdue Univ. Dept. of Geosci. and Geol. Soc. Am. North-Central Section Guidebook 5, 39 pp.

Stacey, F.D. and Banerjee, S.K., 1974. The Physical Principles of Rock Magnetism. Elsevier, New York, N.Y., 195 pp.

Strangway, D.W., Honea, R.M., McMahon, B.E. and Larson, E.E., 1968. The magnetic properties of naturally occurring goethite. Geophys. J. Astron. Soc., 15: 345-359.

Suk, D., Van der Voo, R. and Peacor, D.R., 1990a. Scanning and transmission electron microscope observations of magnetite and other iron phases in Ordovician carbonates from East Tennessee. J. Geophys. Res., 95: 12,327-12,336.

Suk, D., Peacor, D.R. and Van der Voo, R., 1990b. Replacement of pyrite framboids by magnetite in limestone and implications for paleomagnetism. Nature, 345: 611-613.

Suk, D., Van der Voo, R. and Peacor, D.R., 1992. Origin of magnetite responsible for remagnetization of Early Paleozoic limestones of New York State, J. Geophys. Res., in press.

Sundermann, J.A., 1980. Submarine carbonate cementation and pisolith growth in Silurian reefs of northern Indiana (abstract). Am. Assoc. Petrol. Geol. Bull., 64: 790. 